\title{
Hemşirelik bakımında kültürel özellikleri tanılama rehberi
}

\author{
Gülbu Tanrıverdi * \\ Ümit Sevĭg ** \\ Meral Bayat ** \\ M. Cüneyt Birkök ***
}

\begin{abstract}
Özet
Kültürel model ve rehberlerin kullanılması, hemşirelerin bakım verdikleri toplumun kültürel özelliklerini değerlendirmesinde, kültürel verilere daha sistematik ve standardize yollarla ulaşmasında ve kültürlerarası hemşirelik alanında bilgi birikiminin artmasında yararlı olmaktadır. Böylece hemşireler bakım verdikleri bireylerin sağlık ve hastalık davranışları arkasındaki kültürel faktörleri bilir ve bakım verdikleri kişilerle aralarında olası gelişebilecek ve bakıma olumsuz yansıyacak bir algılama ya da davranış yaşanması engellenir. Bunların sonucunda hemşirelerin bireylere sunduğu bakımın kalitesi yükselir. Ülkemizde hemşirelik bakımında yaygın olmamakla birlikte model ve rehberler kullanılmaktadır. Ancak bunlar bireyden, kültürel veri toplamada yetersiz kalmaktadır. Ülkemizde hemşirelik bakımında bu yetersizliği gidermeye yönelik bir model ya da rehbere gereksinim duyulmaktadır. Bu amaçla araştırmacılar, Hemşirelik Bakımında Kültürel Özellikleri Tanılama Rehberi'ni hazırladı. Rehber kültürel özellikleri tanımlayan dört alandan oluşturuldu. Bunlar; bireysel özellikler, iletişim özellikleri, aile içi ve toplumsal roller ve sağlık uygulamalarıdır. Rehberin kliniklerde ve alanda kullanılması, geliştirilerek diğer sağlık çalışanları tarafindan da kullanılması önerilebilir.
\end{abstract}

Anahtar Kelimeler: Hemşirelik bakımı, kültürel özellikler, tanılama, rehber

\footnotetext{
Bu çalışma 3.Uluslararası 10.Ulusal Hemşirelik Kongresinde sunulmuştur.

* Yrd. Doç.Dr.Gülbu Tanrıverdi, gulbu@comu.edu.tr, Çanakkale Onsekiz Mart Üniversitesi, Sağlık Yüksekokulu

** Prof. Dr. Ümit Seviğ, usevig@erciyes.edu.tr, Yrd. Doç.Dr. Meral Bayat, mbayat@erciyes.edu.tr, Erciyes Üniversitesi, Atatürk Sağlık Yüksekokulu

*** Yrd. Doç. Dr. M. Cüneyt Birkök, birkok@sakarya.edu.tr, Sakarya Üniversitesi, Eğitim Fakültesi
} 


\title{
A guide for identifying cultural features in nursing care
}

\begin{abstract}
Use of cultural models and guides is useful in accessing cultural data in a more systematical and standardized manner and in increasing information accumulated on inter-cultural nursing field. Thus, nurses should know the cultural factors underlying health and disease related attitudes of individuals who provide healthcare, and occurrence of any possible cultural shock between nurse and cared individual is avoided. As a consequence, quality of care provided by nurses to individuals is increased. Although not common in our country, models and guides are widely used in nursing care. However, these are not adequate for collecting cultural data from individuals. In our country, a model which can serve as a guide is needed to remove this deficiency in nursing care. For this purpose, "Guide for Identifying Cultural Features in Nursing Care" is developed. This guide is consisted of four fields identifying cultural features which are as follows: personal features, communication features, familial and social roles as well as healthcare procedures. The use and development of this guide in clinics, in the field, and by other healthcare professionals is recommended.
\end{abstract}

Key Words: Nursing care, cultural features, identifying, guide 


\section{GíRiş}

Günümüzde hemşirelik, profesyonel kimliğini topluma en iyi göstermek ve sağllk sistemi içinde görünür olmak için ortak dil oluşturma çabası içindedir (Gordon, 2003). Bu amaçla hemşirelikte modellerinin, sınıflandırma sistemlerinin ve rehberlerinin kullanımı yaygınlaşmaktadır. Modeller, hemşireliğin yaşam, sağlık, hastalık ve toplumla ilgili kavram ve kuramlarla ilişsisini analiz eder, düşüncelerini organize etmeyi kolaylaştırır, meslek üyeleri arasında ortak dil konuşmayı sağlar (Leininger 2002, Ay 2008). Uluslararası Hemşireler Birliği (ICN) 1989 Seul Konferansında Dünya Sağlı Örgütüne (WHO) üye olan ülkelerin hemşirelerini, kendi toplumlarına uyarlanabilir modeller için çalışmaya davet etmiştir (Erdoğan, 2000). Konu ile ilgili olarak, Türkiye'de yapılan araştırmalar hemşirelerin bakımda kullanacakları sınıflama listeleri ve rehberlere gereksinim duyduklarını ve böylece bakım verilen bireylere yönelik daha kısa sürede, daha sistematik ve daha çok bilgiye ulaşılacakları yönündedir (Ay 2003, Ay 2008).

Türkiye'de hemşirelik bakımında; yurt dışında geliştirilmiş modeller, sınıflandırma sistemleri Türkçeye çevrilerek ya da kliniklere özgü yeni rehberler geliştirilerek kullanılmaktadır. Bunlar arasında NANDA'nın tanıları, Gordon'un Fonksiyonel Sağlık Örüntüleri, NIC, NOC ve Günlük Yaşam Aktiviteleri ve OMAHA sistemi yer almaktadır (Erdoğan ve ark. 1999, Hatipoğlu ve ark. 2003, Öz ve ark. 2003, Kangal ve ark, 2003, Öztunca ve ark. 2003, Karaca ve Özaltın 2003, Nico 2003, Turkay ve ark. 2003, Tezel and Gozum 2006, Erdoğan and Esin 2006, Özer ve Kuzu 2006). Ancak bu modeller bakıma 1şık tutacak detaylı kültürel veri toplamada yetersiz kalmaktadır. Yeterli kültürel veri toplayamayan hemşire, bakım verdiği bireyin davranışlarının altında yatan kültürel nedenleri analiz edememekte ve bireylerin sağlı hizmetini kabul etmeme, hizmetten etkili yararlanmama nedenlerini değerlendirilememektedir. Konuyla ilgili olarak Türkiye'de yapılan çalışmalar göstermiştir ki hemşirelik ve ebelik öğrencileri özellikle iletişim, dini inanç ve yaşam biçimi kendisininkinden farklı olan bireylere bakım verirken güçlük yaşamaktadır (Tortumluoğlu ve ark., 2006, Tortumluoğlu ve ark. 2007).

Hemşirelerin, bireyleri kendi kültürel kalıplarında incelemeleri ve hemşirelik yaklaşımında da bunu göz önünde bulundurmaları gerekmektedir (Birol 2000, Duffy, 2001). Hemşireler, bireylerle ilk iletişim kurdukları zaman kültürel değerlendirme yapmalıdırlar. $\mathrm{Bu}$ değerlendirme derinlemesine olacağı gibi daha sonra yapılabilecek derinlemesine bir değerlendirmeye zemin de oluşturabilir. Böylece hemşire topladığı bilgilerle etkili bir iletişime geçme olanağı bulur (Degazon 1996, Duffy 2001). 
Türkiye'de son yıllarda kültürel bakımın ve kültürel veri toplamanın önemine yönelik farkındalık artmıştır. Ancak bu amaçla Türkiye'de geliştirilmiş bir model veya rehber bulunmamaktadır. Bununla birlikte yurt dışında başta Leininger olmak üzere Spector, Giger, Davidhizar, Purnell, Campinha-Bacote gibi birçok uzman hemşire kültürel model ve rehber geliştirmişlerdir (Dowd et al. 1998; Falco, Lobo 1995; George 1990; Giger, Davidhizar 2002; Purnell 2002, Spector 2000; Campinha Bacote et al. 2000). Öncelikle bu modeller derinlemesine incelenmiş ve Türkçeye çevrilerek kültürel değerlendirmede kullanılmıştır (Tortumluoğlu ve ark. 2005, Tortumluoğlu 2005, Tortumluoğlu 2008). Ancak bu modellerin derinlemesine yapılacak bir kültürel değerlendirmede profesyonel bilgi birikimi gerektirdiği ve hemşireler tarafından kullanımının ortak dil sağlamada sorun oluşturabileceği gözlemlendi. Tortumluoğlu ve arkadaşları (2005) kırsal alandaki bireylerin kültürel özelliklerini tanılamada Giger ve Davidhizar'ın Kültürel Değerlendirme Modeli'ni kullanmış ve modelin tanılama alanlarının yeterince açık olmadığını, hemşireler arasında subjektifliğe neden olabileceğini gözlemlemişlerdir. Bu amaçla hemşirelik bakımında derinlemesine kültürel değerlendirme yapmada yol gösterecek ve hemşirelerin meslektaşları ile aralarında ortak dil oluşturacakları bir rehber hazırland1.

$\mathrm{Bu}$ rehber hazırlanırken konuyla ilgili model ve rehberler değerlendirildi. Sağlık üzerinde etkili olan kültürel özellikler belirlendi. Bireyin göç durumu, dini, etnik yapısı, iletişim özellikleri, toplum içindeki rol ve görevleri, sağlığ1 ve hastalığı nasıl algıladığı, sağlığı koruma ve geliştirme davranışları, hastalıklarla baş etme uygulamaları, ekonomik durum, aile yapısı, cinsiyet rolleri, evlilik örüntüleri, cinsel davranış, önleyici örüntüler, nüfus politikası, hamilelik ve doğum pratikleri, vücut imajındaki değişiklikler, beslenme, giyinme, kişisel hijyen, konut düzenlemeleri, genel sağlık düzenlemeleri, meslekler, alışkanlıklar, kültüre bağlı stres, madde kullanımı, boş zaman alışkanlıkları ve kendi kendine tedavi stratejileri ve terapilerin sağlığı etkileyen kültürel özellikler arasında olduğu görüldü (George 1990, Falco and Lobo 1995, Narayan 1997, Dowd et al. 1998, Karadakovan 1998, Campinha Bacote et al. 2000, Cirhinlioğlu 2001, Spector 2000, Purnell 2002, Giger, Davidhizar 2002; Tortumluoğlu ve Ark, 2004, Tortumluoğlu ve Erci, 2004, Bolsoy ve Sevil 2006, Purnell 2008, Tortumluoğlu 2008). Bu bağlamda rehber konuyla ilgili araştırmalar, modeller ve uzman görüşleri alınarak biçimlendirildi. Önce ana başlıklar oluşturuldu. Sonrasında alt başlıklar oluşturularak hemşirelerin daha kısa sürede daha çok bilgiye ulaşması hedeflendi. 


\section{HEMŞİRELİK BAKIMINDA KÜLTÜREL ÖZELLİKLERİ TANILAMA REHBERİ}

Amaç: Kültürel özellikleri tanılamak

Kullanma alanları: Öncelikle evde bakım, halk sağlığı uygulamaları başta olmak üzere hemşirelik bakımının olduğu her alanda kullanılabilir.

Kullanma sınırlılıkları: Rehberin kullanımı zaman almasından dolayı daha çok alanda ve uzun süreli bakım verilen bireyler için uygundur.

\section{Kültürel Özellikleri Tanılama Alanları}

Kültürel özellikler 4 ana alanda tanımlandı.

\section{Alan 1: Bireysel Özellikler:}

\subsection{Ekonomik durum}

1.2.Aile yapıs1 (ataerkil aile yapıs1, anaerkil aile yapıs1)

1.3.Evlilik örüntüsü (çok eşli, tek eşli evlilik, akraba evliliği, endogamik-egzogamik evlilikler, diğer).

1.4.Doğduğu yer, göç durumu, göç nedeni, kaç yıl önce göç geldiği, bugünkü yerleşim birimi

1.5.Geleneksel giyinme biçimi

\subsection{Dinsel Özellikler}

1.6.1. Bireyin hangi dine mensup olduğu

1.6.2. Dini uygulamaları (örtünmek, namaz kılmak, oruç tutmak, abdest almak, dini törenler, dini bayramlar, ibadet yerlerine gitmek vb.)

1.6.3. Sağlı̆̆ı olumlu etkileyen dini uygulamalar (alkol kullanmamak, tek eşlilik, ölü hayvan eti yememek vb.)

1.6.4. Sağlığı olumsuz etkileyen dini uygulamalar (gerekli olduğu halde sağlık çalışanının karşı cinsten olması nedeniyle hizmeti reddetmek, sağlıkla ilgili olumsuz gelişmeleri kadere bırakarak bir şey yapmamak, düzenli beslenmesi gereken bir kronik hastanın oruç tutması vb)

\subsection{Etnik özellikler}

1.7.1.Bireyin etnik kökeni

1.7.2.Etnik yapının özellikleri

1.7.3. Etnik yapıya özgü uygulamalar

1.7.4. Sağlığa olumlu etki eden etnik uygulamalar 
1.7.5. Sağlı̆̆a olumsuz etki eden etnik uygulamalar

1.8. Diğer bireysel özellikler

\section{Alan 2: İletișim Özellikleri:}

\subsection{Ana dil}

2.1.1. Ana dilin hangisi olduğu

2.1.2. Eğer ana dil Türkçe değil ise Türkçenin ne kadar iyi bilindiği

2.1.3.Ana dilini iletişimde ne sıklıkla kullandığ

2.1.4.Ana dilini hangi tür iletişimlerde kullandiğ

2.1.5.Ana dilini sağlık çalışanları ile iletişimde kullanma durumu

2.1.6.Ana dilini sağlık çalışanı ile iletişimlerde kullanamamaktan kaynaklanan güçlükler

2.2. Lehçe, Şive, Ağız

2.2.1. Hangi lehçe, şive ve ağızla konuşulduğu

2.2.2. Lehçe, şive ve ağızla günlük yaşamda konuşma durumu

2.2.3. Lehçe, şive ve ağızla sağlık personeli ile konuşma durumu

2.2.4. Sağlık personeliyle olan iletişimlerde lehçe, şive ve ağızla konuşuyor olmanın güçlükleri

2.3.Selamlaşma ve hitap şekli

2.3.1.Hemcinsle selamlaşma şekli

2.3.2. Karşı cinsle selamlaşma şekli

2.3.3. Selamlaşma şekline etki eden faktörler

2.3.4. Hitap şekline etki eden faktörler

2.3.5.Sağlık personeli ile selamlaşma şekli

2.3.6.Sağlık personeline hitap şekli (hemşire hanım, kızım, yavrum vb)

2.3.7. Sağlık personeli ile selamlaşma şeklinden kaynaklanan sorunlar

2.3.8.Sağl1k personeline hitap şeklinden kaynaklanan sorunlar

\subsection{Ses}

2.4.1.Hangi durumlarda sesin yükseltildiği (sevinç, gerginlik, heyecan vb)

2.4.2. Hangi durumlarda sessizliğin tercih edildiği (üzüntü, saygı, hastalık, korku, endişe vb)

\subsection{Dokunma}

2.5.1.Dokunmanın ne anlama geldiği (sevgi, ilgi diğer) 
2.5.2.Dokunmaya engel teşkil eden faktörler

2.5.3. Sağlık çalışanının dokunması gereken durumlardaki engeller (sağlık çalışanının karşı cinsten olması, işlemin yakın mesafe gerektirmesi, dokunulacak vücut bölgesi özellikle ağız, meme, cinsel organlara yönelik dokunma, diğer)

\subsection{Göz temas1}

2.6.1.Göz temasının ne anlama geldiği (sevgi, ilgi, saygısızlık, diğer)

2.6.2.Göz teması kurmadaki engeller (karşı cinsten olma, diğer)

2.6.3.Sağlık çalışanı ile göz teması kurmada engel olup olmadığı

\subsection{Mesafe}

2.7.1 İletişimde hangi mesafenin tercih edildiği

2.7.2.İletişimde aradaki mesafeyi nelerin belirlediği (karşıdakinin hem cins olması, tanıdık olması, aileden biri olması vb)

2.7.3.Sağlık çalışanı ile mesafeyi belirleme sınırlılıkların olup olmadığ

2.8. Diğer iletişim özellikleri

\section{Alan 3: Aile içi ve toplumsal roller}

3.1 Aile içi roller

3.1.1.Aile reisinin kim olduğu

3.1.2.Ailede kararların nasıl ve kim tarafindan verildiği

3.1.3.Ailede kararlara katılma durumu

3.1.4.Ailede kadının rolü

3.1.5.Ailede erkeğin rolü

3.1.6. Ailede çocuğun rolü

3.1.7. Ailede yaşlının rolü

3.2.Toplumsal Roller

3.2.1. Erkeğin rolü

3.2.1.1.Bekar erkeğin rolü

3.2.1.2.Evli erkeğin rolü

3.2.1.3.Boşanmış erkeğin rolü

3.2.1.4.Dul erkeğin rolü

3.2.2 Kadının rolü

3.2.2.1.Bekar kadının rolü 
3.2.2.2.Evli kadının rolü

3.2.2.3. Gebe kadının rolü

3.2.2.4.Boşanmış kadının rolü

3.2.2.5. Bekar anne olan kadının rolü

3.2.2.6. Dul kadının rolü

3.2.2.7. Çalışan kadının rolü

3.2.3. Çocuğun rolü

3.2.4. Yaşlının rolü

3.3. Diğer aile içi ve toplumsal roller

\section{Alan 4: Sağlık ve hastalık uygulamaları}

4.1. Bireylerin sağlık ve hastalık tanımları

4.1.1.Birey için sağlı̆̆ın tanımı

4.1.2. Birey için hastalığın tanımı

4.1.2. Bireye göre hastalığın nedenleri

4.1.2.1.Kader

4.1.2.2.Kötü şans

4.1.2.3.Kötü ruhlar

4.1.2.4.Allah'ın yapılan bir kötü davranışa yönelik cezası

\subsubsection{Diğer}

4.2.Sağlığı geliştirmeye yönelik geleneksel uygulamalar (beslenme, hijyen, egzersiz, madde kullanımı, diğer alışkanlıklar).

\subsubsection{Beslenme}

4.2.1.1.Besinin anlam

4.2.1.2. Yenilmesi dinen yasak olan yiyecekler

4.2.1.3. Beslenme biçimi

4.2.1.4.Kutsal besinler

4.2.1.5. Özel durumlarda beslenme (hastalık, gebelik, emzirme, menstruasyon gibi)

4.2.4.Hijyen alışkanlıkları

\subsubsection{Egzersiz}

4.2.6.Madde kullanımına bakış

4.2.7.Cinsellik 
4.2.7.1.Cinselliğe yönelik geleneksel uygulamalar

4.2.7.2.Kadın ve erkeğe özgü cinsel normlar

4.2.7.3.Homoseksüelliğin hoş görülmesi veya yasaklanması

4.2.7.4.Cinsel ilişkinin yasaklandı̆̆ durumlar (kadınlarda evlilik öncesi, gebelik dönemi, lohusalık dönemi, emzirme süreci, menstruasyon gibi

\subsubsection{Diğer}

4.3. Sağlı̆̆ korumaya yönelik uygulamalar

4.3.1.Bitki kullanımı

4.3.2. Muska takma

4.3.3.Yatır ve türbelere gitme

4.3.4.Nazarlık takma

4.3.5.Nazar duaları okuma

4.3.6.Geleneksel şifa verenlere gitme

4.3.7.Diğer

4.4. Hastalıkların tedavisine yönelik geleneksel uygulamalar

4.4.1.Hastalıkların tedavisinde ne tür geleneksel uygulamalara başvurulduğu

4.4.1.1.Geleneksel ilaçlar (ot vb)

4.4.1.2.Yatır ve türbelere gitme

4.4.1.3.Geleneksel şifa verenlere gitme (Şeyh, üfürükçü, kırık-çıkıkç1, $\mathrm{vb)}$

4.4.1.4.Muska yazdirma

4.4.1.5.Hastalığa neden olduğu düşünülen kötü ruhu bedenden çıkartma, büyü bozma ve yaptırma

4.4.1.5.Diğger geleneksel tedaviler

4.5. Gebelik, doğum, lohusalığa yönelik geleneksel uygulamalar

4.5.1.Gebe kalmaya yönelik geleneksel uygulamalar

4.5.2.Gebelik dönemine yönelik geleneksel uygulamalar

4.5.3.Gebeliği önlemeye yönelik geleneksel uygulamalar

4.5.4. Gebeliği sonlandırmaya yönelik geleneksel uygulamalar

4.5.5. Doğuma yönelik geleneksel uygulamalar

4.5.5.1.Doğumun kolay olmasına yönelik geleneksel uygulamalar

4.5.5.2.Plesantaya yönelik geleneksel uygulamalar (cami, okul vb yerlerin duvar diplerine gömme, vb) 
4.5.5.3. Doğuma yönelik diğer geleneksel uygulamalar

4.5.6.Lohusalık dönemine yönelik geleneksel uygulamalar

4.5.6.1.Lohusanın beslenmesine yönelik geleneksel uygulamalar

4.5.6.2.Uterus involüsyonunu gerçekleştirmeye yönelik geleneksel uygulamalar

4.5.6.3.Süt salınışını artırmaya yönelik geleneksel uygulamalar

4.5.6.4.Doğum sonu psikolojik problemlere yönelik geleneksel uygulamalar

4.5.6.5.Doğum sonu meme başı çatlaklarını tedavi etmeye yönelik geleneksel uygulamalar

4.5.6.6.Lohusalık dönemine yönelik diğer geleneksel uygulamalar

4.6. İnfertiliteye yönelik geleneksel uygulamalar

4.7.Bebeklik dönemine yönelik geleneksel uygulamalar

4.7.1.Bebek bakımına yönelik geleneksel uygulamalar

4.7.1.1.Emzirme (Emzirmeye başlama zamanı, sütün fazla olması için yapılan uygulamalar, sütten kesme zamanı)

4.7.1.2.Bebeğin göbek bakımına yönelik geleneksel uygulamalar

4.7.1.3.Bebeğin ek besinlere geçme biçimi ve zamanına yönelik geleneksel uygulamalar

\subsubsection{Kundaklama}

4.7.1.5.Bebeğin hijyenine yönelik geleneksel uygulamalar (tırnak kesimi, banyo, konağı giderme biçimi, höllük kullanımı, diğer)

4.7.1.6.Bebeği kolay uyutmaya yönelik geleneksel uygulamalar

4.7.1.7.Bebek bakımına yönelik diğer geleneksel uygulamalar

4.7.2.Bebekte yaygın görülen sağlık sorunlarına yönelik geleneksel uygulamalar

4.7.2.1. Fizyolojik sarılığa yönelik geleneksel uygulamalar

4.7.2.2.Pamukçuğa yönelik geleneksel uygulamalar

4.7.2.3.Pişiğe yönelik geleneksel uygulamalar

4.7.2.4.Gaz sancısını gidermeye yönelik geleneksel uygulamalar

4.7.2.5.Kabızlı̆̆ gidermeye yönelik geleneksel uygulamalar

4.7.2.6.İshali gidermeye yönelik geleneksel uygulamalar

4.7.2.7.Diğer uygulamalar 
4.8. Çocuk bakımına yönelik geleneksel uygulamalar

4.9. Kronik hastalıklara yönelik geleneksel uygulamalar

4.10. Yaygın görülen sağlık problemlerine yönelik geleneksel uygulamalar

4.10.1.Yanıklarda geleneksel uygulamalar

4.10.2. Kırık-çıkıkta geleneksel uygulamalar

4.10.3. Zehirlenmelerde geleneksel uygulamalar

4.10.4. Kanamalarda geleneksel uygulamalar

4.10.5. Gripal enfeksiyonlarda geleneksel uygulamalar

4.10.6. Ağrıya yönelik geleneksel uygulamalar

4.10.7.Diğer yaygın görülen sağlık problemlerine yönelik geleneksel uygulamalar

4.11. Psikiyatrik hastalara yönelik geleneksel uygulamalar

4.12. Menopoz dönemindeki kadınlara yönelik geleneksel uygulamalar

4.12.1. Menopozun algılanış biçimi

4.12.2. Menopoza yönelik tutum

4.12.3. Menopoz dönemindeki yakınmalarla geleneksel baş etme yolları

4.13.Ölüm ve ölmek üzere olan bireylere yönelik geleneksel uygulamalar

4.13.1 Ölüme bakış

4.13.2. Ölüme hazırlık davranışları

4.13.3.Gömme uygulamaları

4.13.4.Keder davranışları

4.14.Diğer uygulamalar

\section{Sonuç ve Öneriler}

Hemşirelerin birey, aile ve topluma istendik düzeyde bakım verebilmeleri için sağlık ve hastalık davranışların arkasında yatan kültürel özellikleri tanımaları önemlidir. Türkiye’de bütün hemşireler tarafından ortak olarak kullanılan kültürel özellikleri tanılamak için spesifik bir model ya da rehber mevcut değildir. Alanda ve kliniklerde kullanılan rehber ve modeller kültürel veri toplamada yetersiz kalmaktadır. Hemşirelerin daha kısa zamanda, daha fazla kültürel veri toplayarak bakımda ortak bir dil oluşturup kültürel değerlendirme yapmasına katkı sağlayacak bir rehbere gereksinim duyulmaktadır. Bu amaçla araştırmacılar Hemşirelik Bakımında Kültürel Özellikleri Tanılama Rehberi'ni oluşturdular. Rehberin amacı kültürel özellikleri tanılamak ve hemşirelik bakımının kalitesine katkı sağlamaktır. Rehber dört 
alandan oluşmaktadır. Bunlar; bireysel özellikler, iletişim özellikleri, aile içi ve toplumsal roller, sağlık ve hastalık uygulamalarıdır.

Rehber sahada aile izlemlerinde derinlemesine bir kültürel değerlendirme yapmak amacıyla halk sağlığı hemşireleri, aile hekimleri, aile sağlığı elemanları ve ebeler tarafından kullanılacağı gibi doğum, çocuk, onkoloji klinikleri başta olmak üzere diğer bütün kliniklerde kültürel veri toplamak amacıyla kullanılabilir. Rehberin tamamı derinlemesine yapılacak bir kültürel değerlendirmede kullanılacağı gibi bir bölümü kullanılarak kısmı bir kültürel değerlendirme de yapılabilir. Bu rehber hizmet verilecek birey, aile ve toplumun kültürel özelliklerini değerlendirmek amacıyla diğer tüm sağlık çalışanları tarafından da kullanılabilir.

\section{Kaynaklar}

Ay F. Hemşirelik Yüksekokulu II. Sınıf öğrencilerinin bakım planlarında sıklıkla kullandıkları hemşirelik tanılarının belirlenmesi. Hemşirelik Sınıflama Sistemleri. Klinik uygulama, eğitim, araştırma ve yönetimde kullanımı. Ankara: Başkent Üniversitesi Basın Yayın ve Halkla İlişkiler Bürosu; 2003:129-139.

Ay F. Uluslararası alanda kullanılan hemşirelik tanıları ve uygulamaları sınıflandırma sistemleri. Türkiye Klinikleri J Med Sci. 2008:555-561.

Birol L . Hemşirelik Süreci. İzmir, Bozkaya Matbaacılık. 2000.

Bolsoy N, Sevil Ü. Sağlık-hastalık ve kültür etkileşimi. Atatürk Üniversitesi Hemşirelik Yüksekokulu Dergisi 2006;9(3):78-87.

Campinha-Bacote J, Yahle T, Langenkamp M. The challenge of cultural diversty for nurse educators. J Contin Educ Nurs 2000; 27: 59-64.

Cirhinlioğlu Z. Sağlık Sosyolojisi. Nobel Kitapevi. Ankara 2001.

Degazon C. Cultural diversity and community health nursing practice. In: Stanhope M, Lancoster J (Eds.). Community Health Nursing. Mosby-year Book, Baltimore. s.117134.

Dowd SB, Giger JN, Davidhizar R. Use of Giger and Davidhizar's transcultural assesment model by health professions. Int. Nurs. Rev 1998; 45(4): 119-23.

Duffy ME. A critique of cultural education in nursing. Journal of Advanced Nursing 2001;36:487-495.

Erdogan S, Esin N. The Turkish version of the Omaha System: its use in practice-based family nursing education. Nurse Educ Today. 2006;26(5):396-402.

Erdoğan S (Editor). OMAHA Sistemi Halk Sağlı̆̆ı Hemşireliği Uygulama Rehberi. İstanbul:AB Ofset; 2000. 
Tanrıverdi, G., Seviğ, Ü., Bayat, M., Birkök, M. C. (2009). Hemşirelik bakımında kültürel özellikleri tanılama rehberi. Uluslararası Ínsan Bilimleri Dergisi [Bağlantıda]. 6:1. Erişim: http://www.insanbilimleri.com

Erdoğan S, Nahcıvan N, Esin N, Çalışklan M, Demirezen E, Coşansu GK. Omaha Sistemi hemşirelik sınıflandırma modelinin halk sağlı̆̆ eğitiminde kullanılması. VII: Ulusal Hemşirelik Kongresi Kitabı. 22-24 Haziran 1999, Erzurum. s.122-129.

Falco SM, Lobo ML. Nursing theories: Madeleine Leininger. George JB (Ed), Norwalk: Appleton and Lange, A Simon and Schuster Company;1995.

George JB. Madeleine Leininger. Nursing Theories The Base Efor Professional Nursing Practice. George JB (Ed) Third edition. Prentice-Hall Int. Inc.1990333-350.

Giger JN, Davidhizar R. The Giger and Davidhizar Transcultural Assesment Model. Journal of Transcultural Nursing 2002;13 (3):185-188.

Gordon M . Why do we need standarized nursing languages? Historical development of the nursing classification systems- An Overview. Hemşirelik Sınıflama Sistemleri. Klinik uygulama, eğitim, araştırma ve yönetimde kullanımı. Ankara: Başkent Üniversitesi Basın Yayın ve Halkla İlişkiler Bürosu; 2003;11-17.

Gök Özer F, Kuzu N. Öğrenci bakım planlarında hemşirelik süreci ve NANDA tanılarını kullanma durumları. Ege Üniversitesi Hemşirelik Yüksekokulu Dergisi 2006; 22(1):69-80.

Hatipoğlu S, Dal U, Yava A, Tastan S, İyigün E. Gordon'un fonksiyonel sağlık örüntüleri modeline göre cerrahi hastalıkları hemşireliği uygulamalarımız. Hemşirelik Sınıflama Sistemleri. Klinik uygulama, eğitim, araştırma ve yönetimde kullanımı. Ankara: Başkent Üniversitesi Basın Yayın ve Halkla İlişkiler Bürosu; 2003;97-107.

Kangal T, Küçükkkaya M, Haberal A, Vatandaş A, Hanoğlu Z, Doğan N. İstanbul Diyaliz merkezinde diyalize giren hastaların bakımında hemşirelik tanılarının, hemşirelik girişimlerinin ve hemşirelik sonuçlarının kullanım özelliklerinin belirlenmesi. Hemşirelik Sınıflama Sistemleri. Klinik uygulama, eğitim, araştırma ve yönetimde kullanımı. Ankara: Başkent Üniversitesi Basın Yayın ve Halkla İlişkiler Bürosu; 2003;237-248.

Karaca A, Özaltın G. Düzce il merkezinde yaşayan yaşlı bireylerin Sosyodemografik özellikleri ve bakım gereksinimlerinin saptanması. Hemşirelik Sınıflama Sistemleri. Klinik uygulama, eğitim, araştırma ve yönetimde kullanımı. Ankara: Başkent Üniversitesi Basın Yayın ve Halkla İlişkiler Bürosu; 2003;277-290.

Karadakovan A. Türk kültüründe sağlık uygulamaları ve kalite. Hemşirelik Ebelik Eğitim ve Uygulamalarında Kalite Sempozyumu, Kayseri 1998

Leininger M. Culture care theory, research, and practice. Nurs Sci Q 2002; 9: 71-78.

Narayan MC. Cultural assesment in Home health care. Home Health Nurse 1997;15:663-670.

Nico EO. Some healthcare classifications relevant to nursing in Europe- An Overview. In: Erdemir F, Yılmaz E, Editors. Hemşirelik Sınıflama Sistemleri. Klinik uygulama, eğitim, araştırma ve yönetimde kullanımı. Ankara: Başkent Üniversitesi Basın Yayın ve Halkla İlişkiler Bürosu; 2003. s. 73-86.

Öz F, Babaoğlu E, Arı F. Hemşirelik yüksekokulu son sınıf öğrencilerinin toplum ruh sağlığı uygulamasında ele aldıkları hemşirelik tanıları. Hemşirelik Sınıflama Sistemleri. Klinik uygulama, eğitim, araştırma ve yönetimde kullanımı. Ankara: Başkent Üniversitesi Basın Yayın ve Halkla İlişkiler Bürosu; 2003;189-198. 
Öztunca İ, Şahin Z, Temurlenk h, Bulut N, Akan D, Algıer L, Abbasoğlu A, Yılmaz E. Serebrovasküler olay geçirmiş olan hastalarda kullanılan hemşirelik tanıları ve hemşirelik girişimleri. Hemşirelik Sınıflama Sistemleri. Klinik uygulama, eğitim, araştırma ve yönetimde kullanımı. Ankara: Başkent Üniversitesi Basın Yayın ve Halkla İlişkiler Bürosu; 2003;257-264.

Purnell L, Paulanca BJ, (Editors). Trascultural Health Care: A Culturally Competent Approach. Philadelphia: F. A. Davis Plus; 2008.

Purnell L. The Purnell Model for Cultural Competence. Journal of Transcultural Nursing 2002;13(3):193-196.

Sayan A. Kültür ve Sağlık. Atatürk Üniversitesi Hemşirelik Yüksekokulu Dergisi1999;2(2):50-52.

Spector RE . Culturel Diversty in Health\&Illness. New Jersey: Prentice Hall Health; 2000.

Tezel A, Gozum S. Comparision of effects of nursing care to problem solving training on levels of depressive symptoms in post partum woman. Patient Education and Counseling 2006:63, 6473.

Tortumluoglu G, Okanlı A, Ozyazıcioglu N, Akyil R. Defining cultural diversities experienced in patient care by nursing students in eastern Turkey. Nurse Education Today 2006;26(2):169-75.

Tortumluoglu G. Heritage of Turkish people. Trascultural Health Care: A Culturally Competent Approach. Purnell L, Paulanca BJ, (Editors). Philadelphia: F. A. Davis Plus; 2008.

Tortumluoğlu G, Bayat M, Seviğ Ü. Bireylerin “Giger ve Davidhizar'ın Transkültürel Değerlendirme Modeli” ile sağlık açısından değerlendirilmesi. 3.Uluslararası 10.Ulusal Hemşirelik Kongre özet Kitabı. Ege üniversitesi hemşirelik Yüksekokulu 7-10 Eylül 2005. İzmir. 2005, s,141.

Tortumluoğlu G, Okanlı A, Özer N. Cultural approach and its significance in nursing. International Journal of Human Sciences 2004. ISSN: 1303-5134. http://www.insanbilimleri.com

Tortumluoğlu G, Okanlı A, Şıpkın S, Özyazıcıoğlu N, Akyıl R (2007). Sağlık Yüksekokulu öğrencilerinin bakım verirken yaşadıkları kültürel deneyimler ve etkileyen faktörler. T.S.K.II üncü Ulusal/Uluslar arası Katılımlı hemşirelik Kongresi. 8-11 Mayıs 2007. Dedeman Ski Lodge, Erzurum.

Tortumluoğlu G. Transkültürel hemşirelik ve kültürel bakım model tanıtımı. Cumhuriyet Üniversitesi HYO Dergisi 2005; 8(2):47-57.

Turkay U, Hacıoğlu F, Erdemir F, Pınar G, Göçer S, Uçku V. Wilm's tümörlü bir çocuğun bakımında hemşirelik tanı ve girişimlerinin kullanımı. Hemşirelik Sınıflama Sistemleri. Klinik uygulama, eğitim, araştırma ve yönetimde kullanımı. Ankara: Başkent Üniversitesi Basın Yayın ve Halkla İlişkiler Bürosu; 2003;265-276. 